\title{
MULHERES CIENTISTAS NO ENFRENTAMENTO À COVID-19
}

\section{WOMEN SCIENTISTS IN THE FIGHT AGAINST COVID-19}

\author{
Anailza Silva Barbosa de Lima* \\ ORCID: https://orcid.org/0000-0003-3546-9960 \\ Jefferson Antônio Marques** \\ ORCID: https://orcid.org/0000-0003-2285-1984 \\ Jucilane Alves dos Santos*** \\ ORCID: https://orcid.org/0000-0001-9028-5246 \\ Maria Izabel de Souza Alencar**** \\ ORCID: https://orcid.org/0000-0002-0377-0997 \\ Mirleide Dantas Lopes***** \\ ORCID: https://orcid.org/0000-0001-9431-3339 \\ Sirleide Dantas Lopes****** \\ ORCID: https://orcid.org/0000-0002-7739-9377
}

\section{Resumo}

Objetiva-se relatar as experiências vivenciadas na execução do projeto "Mulheres cientistas no enfrentamento à COVID-19", vinculado à Universidade Federal de Campina Grande, na Paraíba. Este projeto foi desenvolvido remotamente, em uma escola da rede estadual de ensino. Para tanto, foram realizadas cinco rodas de diálogo, as quais tiveram por objetivo problematizar o papel das mulheres na ciência, através de suas contribuições no enfrentamento à pandemia causada pelo novo coronavírus. Estas atividades foram realizadas entre agosto e dezembro de 2020, com estudantes do nono ano do Ensino Fundamental e das três séries do Ensino Médio, contando com uma audiência média de quarenta alunos. Ao final, foi aplicado um questionário online, por meio do qual avaliou-se satisfatoriamente a participação dos discentes, porém constatou-se que o papel da mulher na ciência ainda precisa ser bastante discutido na educação básica.

Palavras-chave: Mulheres; Ciência; Doença do Coronavírus; Ensino Fundamental e Médio; Extensão Universitária.

\section{Abstract}

This paper describes the experiences lived during the execution of the university outreach project "Women scientists in the fight against COVID-19", linked to the Federal University of Campina Grande (UFCG), in Paraiba, and developed remotely in a public school. To achieve this purpose, five rounds of dialogue were held, problematizing the role of women in science through their contributions to the fight against the pandemic caused by the new coronavirus. These activities were carried out between August and December 2020 with students from the 9th grade of elementary school, and those from the 1st to the 3rd grade of high school, with participation of about forty students. An online questionnaire was applied at the end of the project and the result demonstrated the students' satisfactory participation, in addition to highlighting that the women's role in science needs to be further discussed in basic education.

Keywords: Women; Science; Coronavirus Disease; Elementary and High School; University Outreach.

Data recebimento: $04 / 02 / 2021$

Data de aceite: 18/05/2021
* Aluna de Graduação da Universidade Federal de Campina Grande (UFCG), Campina Grande - PB, Brasil. Email: anailza.silva@estudante.ufcg.edu.br ** Secretário Executivo da Universidade Federal de Campina Grande (UFCG), Campina Grande - PB, Brasil. Email: jeffymarques@gmail.com *** Aluna de Graduação da Universidade Federal de Campina Grande (UFCG), Campina Grande - PB, Brasil. Email: jucilanealves05@gmail.com **** Aluna de Graduação da Universidade Federal de Campina Grande (UFCG), Campina Grande - PB, Brasil. Email: izabelalencar7@gmail.com ***** Professora da Universidade Federal de Campina Grande (UFCG), Campina Grande - PB, Brasil. Email: mirleide@df.ufcg.edu.br ****** Gestora da Escola Cidadã Integral Maria de Lourdes Araújo, Campina Grande - PB, Brasil. Email: ladydantas@hotmail.com 


\section{Introdução}

A trajetória das mulheres ao longo da história foi marcada por preconceitos e segregações. À mercê de uma sociedade machista, conservadora e patriarcal, seus modos de vida eram comumente ditados pelos homens, considerados seus "proprietários". A figura paterna estaria associada ao primeiro proprietário da mulher, e, após o casamento, essa posse passaria para seu cônjuge. Por serem tratadas como o sexo frágil, o espaço público não era considerado um ambiente adequado para elas. Com isso, os homens costumavam confinar as mulheres aos ambientes domésticos, configurando o que hoje definimos como divisão sexual do trabalho (KERGOAT, 2016).

São muitos os registros históricos que revelam as opressões sofridas pelas mulheres. A caça às bruxas, ocorrida entre os séculos XV e XVII, é um movimento bastante emblemático neste sentido. As bruxas, geralmente mulheres pobres e viúvas, detinham conhecimentos sobre a utilização de ervas medicinais e, por essa razão, eram perseguidas, julgadas e queimadas vivas em praças públicas, a fim de servirem de exemplo para aquelas que ousassem ter o mesmo comportamento (SANTOS; TOSI, 1996).

Desenvolver o que hoje é definido como atividade científica era praticamente inconcebível para uma mulher. Tais atividades eram majoritariamente exercidas por homens e a presença feminina na produção do conhecimento científico era considerada uma afronta à moral e aos bons costumes. O pensamento lógico e abstrato, assim como o uso de formulações matemáticas, seria essencial ao exercício das atividades científicas; no entanto, as mulheres eram consideradas intelectualmente inferiores, não estando, portanto, aptas a produzirem conhecimento científico (SCHIEBINGER, 2001).

Na contemporaneidade, a segregação entre o público e o privado ainda define quais são os papéis sociais aceitáveis a depender do sexo e serve de sustentáculo a um modelo de sociedade que oprime e invisibiliza o trabalho das mulheres. Mesmo com toda a emancipação feminina, estas normas sociais que moldam o comportamento de homens e mulheres continuam bastante contundentes e se manifestam desde a infância (OLINTO, 2011).

Atualmente, a pandemia causada pelo SARS-CoV-2, o novo coronavírus, conhecido pela sigla COVID-19 (em inglês, Coronavirus Disease 2019), trouxe diversas dificuldades para as mulheres, principalmente as que possuem filhos, pois além do trabalho já realizado dentro e fora do espaço doméstico, muitas passaram a se responsabilizar ainda mais pela educação dos filhos e filhas, em função do ensino remoto adotado pelas diferentes instituições educacionais (SOUTO-MARCHAND; GALVÃO; FERNANDES, 2020).

Diante da nova realidade pandêmica, o presente artigo objetivou relatar as experiências vivenciadas na execução do projeto de extensão "Mulheres cientistas no enfrentamento à COVID-19", desenvolvido pela Universidade Federal de Campina Grande (UFCG) durante a pandemia. As atividades se desenvolveram em uma escola da rede estadual de ensino da Paraíba, problematizando, junto aos discentes da educação básica, pesquisas realizadas por algumas cientistas que, ao longo da história e na contemporaneidade, deram relevantes contribuições para a ciência, principalmente as que atuaram e ainda atuam de maneira imprescindível no enfrentamento à pandemia causada pelo novo coronavírus. 


\section{Mulher e ciência: da antiguidade à contemporaneidade}

A primeira pessoa do sexo feminino a figurar nos registros históricos como cientista foi a filósofa, matemática e astrônoma Hipátia de Alexandria (370-415 d.C). Por ser mulher, ter conhecimentos avançados sobre filosofia, matemática e astronomia, bem como expor seus saberes ao público no ensino de jovens, sua atuação se configurava como uma quebra de estereótipos entre filósofos da época. Em um contexto de tensões políticas entre igreja e Estado, Hipátia acabou sendo assassinada por cristãos fanáticos (CHASSOT, 2004).

Por muito tempo, a figura feminina teve seu nome apagado da história; inclusive, em algumas situações, isso ocorreu de forma bastante trágica. A partir do século XV, com o surto da caça às bruxas na Europa, muitas mulheres foram criminalizadas pela inquisição. $O$ primeiro movimento, neste sentido, aconteceu aproximadamente entre 1450 e 1520 . Essas perseguições foram retomadas a partir de 1560 e adquiriram proporções gigantescas, atingindo o auge entre 1600 e 1650 (TOSI, 1998).

Com o surgimento do Iluminismo, entre os séculos XVII e XVIII, houve a reforma das ideias, com o uso da razão e a liberdade do pensamento como princípios fundamentais do movimento. No entanto, mesmo havendo grandes reformas políticas e sociais, a mulher continuava sendo considerada um ser frágil, controlada por suas emoções e incapaz de realizar tarefas que não fossem cuidar do lar e desempenhar o papel de uma boa esposa (SCHIEBINGER, 2001).

No decorrer dos séculos, o discurso sobre a imagem feminina foi se modificando, mas não à toa. Mesmo em pleno século XIX, com a ideia ainda impregnada nas mentes e enraizada na sociedade de que a mulher era um ser incapaz intelectualmente e servia apenas para a reprodução, alguns movimentos começaram a surgir. Com isso, surge uma nova ideia do que seria o ser feminino e as mulheres começaram a organizar ações. O intuito das manifestações era combater a discriminação feminina e lutar pelo direito ao voto, tornando-as mais ativas na sociedade. Esses acontecimentos seriam apenas o começo de várias outras reivindicações, que foram caracterizadas como a primeira onda do movimento feminista (ROSA; SILVA, 2012).

Para que fossem ouvidas, muitas mulheres pagaram o preço com suas próprias vidas. Foi o caso da feminista Emily Davison, que, em 1913, na famosa corrida de cavalos que acontecia em Londres, jogou-se em frente ao cavalo que transportava o Rei George V, para chamar a atenção das figuras importantes da época, e acabou falecendo. Um dos motivos era a reivindicação ao sufrágio universal, direito que só foi conquistado no Reino Unido em 1918 (PINTO, 2010).

O final da primeira onda do feminismo é marcado por publicações que serviram para dar impulso à segunda onda. Uma das mulheres de destaque nesse período foi Simone de Beauvoir (1908-1986), especialmente em razão da publicação do livro Segundo sexo: fatos e mitos, em 1970. Simone influenciou e inspirou muitas mulheres com a sua emblemática frase: "Não se nasce mulher, torna-se mulher". A segunda onda ocorre no período após a Segunda Guerra Mundial, com o mundo inteiro passando por mudanças sociais e políticas. Neste cenário, as mulheres reivindicavam políticas públicas que lhes resguardassem em relação à violência doméstica e social, e o livro de Simone de Beauvoir trata justamente sobre o que é ser mulher, tanto no que diz respeito à questão biológica quanto na esfera social. (MARQUES; XAVIER, 2018). 
Com o passar do tempo, as discussões sobre a divisão sexual do trabalho e a atuação da mulher no espaço público começaram a ser repensadas. No entanto, tais transformações não ocorreram de forma repentina. Para que a sociedade possa romper com ideias há séculos enraizadas, os conceitos precisam ser moldados para a nova realidade. Porém, como toda revolução de pensamento desencadeia conflitos, as consequências não estarão ilesas de enfrentamentos (CHASSOT, 2004).

Com tantas reflexões feitas sobre a ideia do que é ser mulher, outros questionamentos e posicionamentos começaram a surgir. O movimento foi caracterizado como a terceira onda do feminismo e teve início em 1990. A terceira onda buscava alcançar todas as mulheres, sem distinção de classe, cor e raça, e compreendia que as opressões por elas sofridas poderiam ocorrer em qualquer ambiente. Ao mesmo tempo, as percepções relativas a tais opressões seriam vivenciadas de forma diferente, a depender da subjetividade de cada uma (MARQUES; XAVIER, 2018).

Em consequência dos movimentos feministas, as mulheres tornaram-se sujeitos políticos e mais ativas dentro da sociedade, rompendo com o modelo tradicional que foi imposto à figura feminina por muitos séculos (MARTINS, 2015). Neste ínterim, as universidades também passaram cada vez mais a despertar o interesse das mulheres pelo ensino superior e, consequentemente, pela produção do conhecimento (BELTRÃO; ALVES, 2009).

Na contemporaneidade, constata-se a presença feminina em campos científicos; porém, ocorre a concentração em algumas áreas, principalmente as relacionadas aos cuidados, como Enfermagem, Pedagogia e Serviço Social. A participação, principalmente nas áreas de Ciências, Tecnologias, Engenharias e Matemática (CTEM), ainda acontece de forma mais restrita e são vários os fatores que influenciam a baixa representatividade de mulheres neste espaço (SILVA; RIBEIRO, 2014).

Há, ainda estudantes que são aprovadas nos cursos das áreas de CTEM e se sentem desestimuladas ao adentrarem na universidade, dado que ainda há um sentimento de menos aceitação da presença feminina nestes cursos, por parte de alguns alunos e professores. Destarte, algumas acabam não querendo enfrentar tais desafios e desistem de atuar nestas áreas (CARVALHO; CASAGRANDE, 2011).

Vale salientar que o topo da hierarquia acadêmica é constituído, majoritariamente, pela figura masculina. Isto acontece porque são os homens quem estabelecem as relações sociais e de poder na ciência (CARVALHO; CASAGRANDE, 2011). Dessa forma, para mulheres que exercem a carreira científica, da qual foram historicamente excluídas, há um desafio a mais, visto que, em uma sociedade repleta de desigualdades, essa realidade áspera também se faz presente na academia. Segundo Chassot (2004), "Quando se busca caracterizar a Ciência, há algo que aparece muito naturalmente e que não necessita de muitos esforços para ser evidenciado: o quanto a Ciência é masculina". Desse modo, quando se busca por representações femininas na ciência, ou em outras áreas que são caracterizadas como masculinas, enfrentase dificuldade para encontrar mulheres nesses espaços.

A realidade dentro da universidade, considerando a atuação na carreira científica, é que existe um percentual baixo de mulheres, devido ao fato de muitas desistirem por não conseguirem conciliar os afazeres domésticos, cuidados com os filhos e a carreira científica 
(LAZZARINI et al., 2018). Sendo assim, como as diferentes áreas exigem compromissos pensados em carreiras científicas masculinas, demandam atenção total e dedicação exclusiva. Por consequência, força as mulheres que buscam seguir suas carreiras a optar por intercalar sua profissão com família e tarefas domésticas, passando, assim, a exercerem uma exaustiva jornada de trabalho (SILVA; RIBEIRO, 2014).

Todavia, ao longo da história algumas mulheres conseguiram destaque, mesmo diante de todas as dificuldades. Além da já citada Hipátia, outra grande cientista, nem tão valorizada na época por ser mulher e estar em uma área majoritariamente masculina, foi Marie Sklodowska Curie, mais conhecida como Madame Curie. Foi a única contemplada com dois Prêmios Nobel em duas ciências distintas. Em 1903, recebeu o Nobel de Física, juntamente com seu esposo Pierre Curie (1859-1906) e Henri Becquerel (1852-1908), por suas descobertas nos estudos da radioatividade (CHASSOT, 2004). Em 1911, recebeu o Nobel de Química por isolar o rádio metálico puro e ter contribuído para o avanço da ciência.

Por vários séculos, as mulheres tiveram que enfrentar diversos obstáculos para ocupar espaço na ciência. A educação e a inclusão feminina em áreas científicas foram e ainda são processos extremamente difíceis; no entanto, a pandemia mostrou que elas estão atuando de forma ativa e assumindo a linha de frente em diversas pesquisas sobre a Covid-19. (STANISCUASKI et al., 2020).

Contemporaneamente, as mulheres passaram a ter mais liberdade, principalmente para atuar nas áreas que desejassem, independentemente dos estereótipos previamente estabelecidos. No entanto, algumas permeiam entre o lugar para elas designado pela sociedade, que seria o de dona do lar, e uma carreira científica (ANTENEODO et al., 2020). O dilema das mulheres cientistas se tornou ainda maior em razão da pandemia pelo novo coronavírus, causador da COVID-19. O primeiro vírus dessa natureza foi descoberto em 1964, em Londres, por June Almeida. June era uma virologista que, a princípio, não conseguiu cursar uma faculdade por questões financeiras; entretanto, quando mudou-se para o Canadá, passou a trabalhar como técnica de laboratório, o que lhe garantiu assinar vários artigos científicos e, posteriormente, um título de doutora, mesmo não possuindo uma graduação (HORA, 2020).

A COVID-19 ganhou proporções globais. Com isso, cientistas do mundo inteiro, inclusive inúmeras mulheres, passaram a decodificar o código genético do vírus, objetivando compreender melhor os mecanismos de propagação da doença, além de desenvolver vacinas que sejam capazes de combater o avanço da pandemia. O novo coronavírus reage de diversas formas no organismo do ser humano e ainda não foi descoberto um padrão para sua manifestação.

No contexto pandêmico, surge no cenário brasileiro a figura de Ester Sabino, imunologista que, acompanhada de sua equipe, realizou o sequenciamento genético do novo coronavírus em um tempo recorde de 48 horas. É importante ressaltar que a equipe de Ester Sabino é composta por 27 pessoas, dentre as quais 17 são mulheres. Uma cientista que também merece destaque nesse grupo é Jaqueline Goes, biomédica que foi de suma importância para compreender o código genético do novo coronavírus. Esse feito foi essencial para entendermos melhor o vírus e, por consequência, a COVID-19 (CRUZ, 2020). 
Na busca pela vacina, muitas mulheres também ocupam posição de destaque. Um exemplo é o grupo de Oxford, que é liderado pela brasileira Daniela Ferreira. De forma análoga a Ester Sabino, Daniela lidera uma equipe formada por 100 pessoas, sendo $98 \%$ dela composta por mulheres (FANTÁSTICO, 2020). Assim como Ester, Jaqueline e Daniela, a cientista Kizzmekia Corbett também ocupa uma posição de destaque no enfrentamento à pandemia causada pela COVID-19, já que lidera mais uma equipe em busca da vacina para o enfrentamento da pandemia. Kizzmekia é imunologista e trabalha no Instituto Nacional de Saúde dos Estados Unidos, no Centro de Pesquisa de Vacinas (SILVEIRA et al., 2020).

A corrida contra o tempo em busca da vacina é notória, mas também há cientistas que pretendem usar o reposicionamento de fármacos no tratamento para a COVID-19, como é o caso da cientista Daniela Trivella e sua equipe (SERRAPILHEIRA, 2020). A vacina precisa de tempo até ser fabricada, por isso o reposicionamento de fármacos seria de grande ajuda no enfrentamento ao novo coronavírus. A técnica consiste basicamente em investigar o potencial de medicamentos já existentes para tratar novas doenças (SERRAPILHEIRA, 2020).

Após a realização de diversos testes com a vacina de Oxford, a primeira voluntária a ser vacinada no Brasil foi a odontóloga brasileira Denise Abranches (CROSP, 2020). Denise atua na linha de frente no enfrentamento à COVID-19, tanto por se voluntariar como por cuidar da saúde bucal de pacientes que estão internados em razão da doença. Ela coordena uma equipe de 25 dentistas e ajuda na capacitação dos profissionais de enfermagem.

É notória a dedicação das mulheres cientistas em meio à pandemia enfrentada por todo o mundo; porém, elas possuem inúmeras dificuldades, já que muitas não são apenas cientistas, mas também são mães. Com o surto causado pelo novo coronavírus, a carga de trabalho direcionada às mães dobrou. As atividades escolares remotas passaram a exigir ainda mais das mulheres, uma vez que são elas as principais responsáveis pelos cuidados com os filhos. No entanto, mesmo exercendo uma carga de trabalho maior, muitas têm atuado na linha de frente da pandemia e são essenciais na luta contra a COVID-19 (ONU MULHERES, 2020).

\section{Metodologia}

O presente trabalho é vinculado à Universidade Federal de Campina Grande (UFCG), na Paraíba e foi desenvolvido virtualmente entre os meses de agosto e dezembro do ano de 2020, na Escola Cidadã Integral Maria de Lourdes Araújo. A equipe executora foi formada por seis pessoas, quais sejam: a professora coordenadora, três alunas do curso de Licenciatura em Física da UFCG, um técnico administrativo da mesma universidade e a gestora escolar.

Nos dois primeiros meses de execução do projeto foram realizadas, apenas com a equipe executora, revisões de literatura, orientadas pela coordenadora, e levantamentos bibliográficos, através do método de exploração, que "tem como finalidade proporcionar mais informações sobre o assunto que vamos investigar, possibilitando sua definição e seu delineamento", conforme Prodanov e Freitas (2013). 
Neste primeiro momento, as buscas quanto aos conteúdos relativos à participação feminina no enfrentamento à pandemia foram realizadas no Google Busca, plataforma com a qual as licenciandas tinham mais afinidade. Tais pesquisas foram direcionadas por reportagens assistidas pela equipe, em diferentes veículos de comunicação, como emissoras de televisão e redes sociais, tendo como exemplos de descritores utilizados "mulher e ciência", "pandemia" e "coronavírus".

Em momento posterior, foram realizadas reuniões virtuais para debater a literatura que fundamenta as discussões sobre a participação da mulher na ciência, bem como os dados relativos à atuação das cientistas no enfrentamento à pandemia causada pela COVID-19. Tais discussões serviram para selecionar os materiais e planejar as rodas de conversa que foram posteriormente realizadas na aludida escola.

Após esta etapa inicial, as licenciandas passaram cerca de um mês e meio atuando na escola, sob a supervisão da coordenadora do projeto, do técnico que atuou como colaborador e da gestora escolar, que também exerceu a função de colaboradora. Esta, inclusive, foi a responsável por conceder a autorização para a execução do projeto, sob a garantia de que fosse preservado o anonimato dos estudantes da escola, caso as atividades realizadas fossem publicadas.

Ao todo, foram realizadas 5 rodas de conversa, que ocorriam uma vez por semana, nas terças-feiras, no último horário da manhã, das $11 \mathrm{~h}$ às $12 \mathrm{~h}$, que correspondia às aulas de Ciências do nono ano do Ensino Fundamental. Contudo, o link da aula era disponibilizado para as 3 turmas do Ensino Médio, e os professores dessas turmas liberavam os estudantes para participarem das atividades do projeto. Naquele momento, a gestora escolar tentava direcionar os alunos de Ensino Médio para a roda de diálogo; todavia, muitos não participavam, o que resultava na audiência média de 40 estudantes para cada atividade realizada.

A primeira roda de conversa foi realizada pela coordenadora, que procedeu com a apresentação do projeto e destacou a participação de algumas cientistas em diferentes períodos históricos, como a filósofa e matemática Hipátia de Alexandria. As demais rodas de conversa foram realizadas pelas licenciandas e tiveram como objetivo discutir questões relacionadas à pandemia, visibilizando o trabalho das mulheres cientistas.

Os diálogos conduzidos pelas discentes buscavam contextualizar temáticas importantes no âmbito do enfrentamento à pandemia, com conteúdos geralmente trabalhados nas disciplinas de Biologia, Física, Matemática e Química. O segundo momento de diálogo falava sobre os vírus de uma maneira geral e, mais especificamente, sobre o SARS-Cov-2 e suas características, como, por exemplo, o sequenciamento genético do vírus e a relevância de sua decodificação. Neste cenário, foram evidenciados os trabalhos das cientistas Ester Sabino e Jaqueline Goes, bem como apresentada a química Rosalind Franklin, primeira pessoa a observar a estrutura em dupla da molécula de DNA, mas que não teve o seu trabalho devidamente reconhecido à época (SILVEIRA et al., 2020).

A terceira roda de conversa esteve mais relacionada a conteúdos próprios da Química; no entanto, toda discussão contextualizada vincula-se de forma interdisciplinar a outras áreas do conhecimento. Especificamente, tratava sobre a questão de fabricação das vacinas e medicamentos, bem como a dificuldade de produzi-los, dando-se ênfase ao trabalho de cientistas como Daniela Trivella e Daniela Ferreira, já citadas neste texto. 
No quarto momento, foram discutidas as modelagens matemáticas no contexto da pandemia e a importância da temática, objetivando-se destacar a relevância da Matemática em todos os espaços da sociedade, por meio da previsibilidade que esta ferramenta favorece. Neste contexto, foram apresentados os trabalhos de mulheres que promovem a divulgação de conteúdos científicos relativos ao enfrentamento da pandemia.

A última roda de diálogo abordou a utilização de exames de radiografia (popularmente conhecidos como raios-X) para tratamento e detecção da COVID-19. Dessa forma, os conteúdos trabalhados estiveram mais relacionados à Física e, por essa razão, foi possível fazer um recorte histórico, a partir do qual foram apresentadas, de forma sucinta, a vida e obra de Marie Curie, cientista que inventou o primeiro veículo utilizado para realizar exames de radiografia que foram realizados na Primeira Guerra Mundial.

Como instrumento de coleta de dados, foi aplicado aos estudantes um questionário online, por meio da plataforma Google Formulários, com perguntas que envolviam conteúdos trabalhados durante as rodas de conversa, especialmente os que diziam respeito à participação feminina na ciência. O questionário foi dividido em duas partes. A primeira objetivava caracterizar os respondentes quanto ao gênero e a série que cursavam. A segunda parte era composta por 9 questões, sendo 8 objetivas, que, de uma forma geral, buscavam identificar como os estudantes da escola avaliaram a execução do projeto, com alternativas de respostas "ruim", "regular", "bom" e "ótimo", além de uma indagação de caráter subjetivo, intencionando-se identificar como os alunos avaliavam o papel da ciência no enfrentamento à pandemia causada pela COVID-19.

Dada a estrutura do questionário, a análise das respostas às questões objetivas foi feita através de cálculos de percentuais que possibilitaram melhor interpretação dos dados levantados. Apenas em uma das questões objetivas, que tratava especificamente sobre como os alunos avaliavam a participação das mulheres cientistas no enfrentamento à pandemia, foi utilizado um gráfico circular para ilustrar melhor os resultados. Quanto à questão subjetiva, foi utilizada análise de conteúdo, através da qual foi realizada uma pré-análise das respostas dos estudantes, consequentemente, uma exploração mais detalhada do material, e, por fim, a realização de inferências e interpretações (GIL, 2008). A etapa de análise de dados e a elaboração de um relatório de atividades foram realizadas no último mês de execução do projeto.

\section{Resultados e discussões}

De um modo geral, a pandemia causada pela COVID-19 tem resultado em um esvaziamento das salas de aula, conforme Souto-Marchand, Galvão e Fernandes (2020), e na escola em que o projeto foi executado isso não foi diferente. Do total de participantes, que girava em torno de 40 estudantes, somente 26 responderam ao questionário, sendo a maioria do nono ano do Ensino Fundamental (79,2\%); 12,5\% do segundo ano do Ensino Médio; 8,3\% do terceiro ano do Ensino Médio; e nenhum do primeiro ano. 
Com relação ao gênero dos respondentes, observa-se que a maioria do público era composta por mulheres, somando um percentual de $66,7 \%$. Entre os demais, $29,2 \%$ se declararam homens, enquanto $4,2 \%$ preferiram não responder.

Quanto à segunda parte do questionário, a primeira pergunta questionava como, de uma maneira geral, os estudantes avaliaram o projeto. Como resultado, constatou-se que $66,7 \%$ avaliaram o projeto como "ótimo", $25 \%$ como "bom" e $8,3 \%$ como "regular", não sendo fornecida nenhuma resposta "ruim". Observando-se os dados, é possível constatar que as rodas de conversa realizadas tiveram avaliação bastante positiva por parte dos estudantes.

Na segunda questão objetiva, os estudantes foram interrogados quanto à atuação das licenciandas na execução do projeto. Constatou-se que as respostas para tal indagação foram positivas, uma vez que 50\% classificaram a atuação como "ótima", 41,7\% como "boa" e 8,3\% como "regular". Mais uma vez, a alternativa "ruim" não foi escolhida pelos estudantes, o que reforça a ideia de que a execução do projeto foi exitosa.

Em seguida, os discentes foram levados a se autoavaliarem quanto à aprendizagem dos conhecimentos relativos à COVID-19, adquiridos através do projeto. Com isso, $25 \%$ dos alunos avaliaram seu aprendizado como "ótimo", 50\% como "bom" e 25\% como "regular", o que é bastante satisfatório, levando-se em consideração que a maioria das respostas foi positiva. No entanto, é possível observar que houve uma queda no percentual "ótimo" quando as respostas são comparadas às anteriores e isso pode estar ligado à falta de segurança dos estudantes em relação aos conteúdos abordados, uma vez que a maioria dos respondentes está no nono ano do Ensino Fundamental.

Os dados iniciais foram muito satisfatórios; porém, quando os respondentes foram interrogados, por meio da quarta questão, se já tinham ouvido falar sobre alguma das cientistas apresentadas durante a execução do projeto, 100\% responderam "não", o que revela um cenário bastante preocupante, uma vez que é constatado que eles estão completamente alheios à atuação feminina na ciência, não tendo, portanto, referências que lhes permitam conjecturar a possibilidade de as mulheres contribuírem nesta área do conhecimento. Tal fato contribui também para que as meninas não se reconheçam exercendo atividades científicas, o que favorece, dessa forma, a baixa diversidade de gênero na área, conforme já aponta a literatura (ANTENEODO et al., 2020). A quinta pergunta solicitava que os estudantes mencionassem as cientistas que conheciam antes da execução do projeto; entretanto, dada as respostas negativas à questão anterior, ela perdeu o sentido.

Visto que o projeto buscou dar visibilidade ao trabalho realizado pelas cientistas que estão atuando no enfrentamento à COVID-19, os estudantes também foram indagados quanto à atuação das mulheres neste enfrentamento. Como resultado, 37,5\% das respostas foram "ótimo", 45,8\% "bom” e 16,7\% "regular", conforme gráfico da Figura 1. Isso implica dizer que $83,3 \%$ dos discentes fizeram uma avaliação positiva, o que é bastante relevante, uma vez que sequer conheciam tais cientistas antes da execução do projeto, reforçando, assim, a importância de iniciativas dessa natureza, como a realizada pelo Projeto de Extensão Universitária "Meninas e Mulheres nas Ciências", da Universidade Federal do Paraná (SILVEIRA et al., 2020). 
Figura 1 - Gráfico das respostas de 26 estudantes da Escola Cidadã Integral Maria de Lourdes Araújo à pergunta: “Como você avalia hoje a participação das mulheres no enfrentamento à pandemia causada pela COVID-19?”.
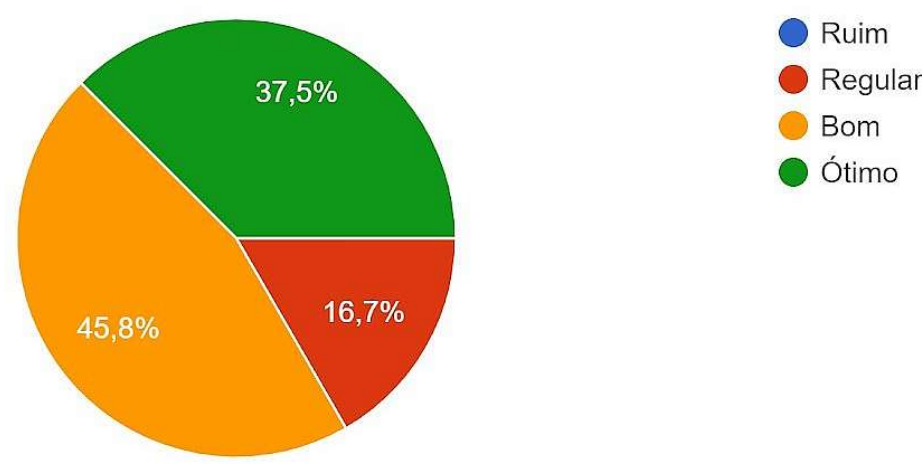

Fonte: autoria própria.

Como já mencionado, em razão da pandemia, todas as atividades relativas ao projeto foram desenvolvidas de forma remota. Dessa maneira, a questão de número 7 indagou os estudantes quanto ao uso das tecnologias digitais, se elas contribuíram para melhor compreensão dos conceitos trabalhados no projeto. Uma parcela de 33,3\% dos respondentes disse "com certeza", $50 \%$ disseram "sim" e 16,7\% disseram "talvez"; ou seja, novamente, a maioria das respostas obtidas é de cunho positivo e deduz-se que, especialmente no contexto pandêmico, é fundamental que o emprego de tecnologias seja cada vez mais utilizado na educação básica.

Na última questão objetiva, os estudantes foram questionados se após a realização do projeto eles se sentiam motivados a seguir uma carreira científica. Constatou-se que $70,8 \%$ disseram "talvez", 16,7\% "sim" e 12,5\% "não". Dessa forma, conclui-se que, apesar de a carreira científica geralmente não ser uma opção para os estudantes, de uma forma geral, e mais especificamente para as mulheres, conforme apontam Pinto e Amorim (2015), o percentual de respondentes que excluiu a possibilidade de atuar nesta área foi pequeno e talvez isso já seja um reflexo da execução do projeto, que também buscava mostrar que as cientistas são pessoas comuns; assim sendo, qualquer um(a) também poderia atuar na área.

A última pergunta do questionário era subjetiva e interrogava da seguinte maneira: "Na sua opinião, qual a importância da ciência no momento pandêmico que estamos vivenciando?". Dado o contexto de ampla divulgação de mitos e informações falsas que a sociedade contemporânea vivencia, a ideia era provocar reflexões sobre o papel da ciência. A partir da análise do conteúdo das respostas, é possível afirmar que todos os respondentes apontaram a ciência 
como ferramenta essencial no momento pandêmico. Alguns apresentaram respostas mais elaboradas, que descreviam, inclusive, a importância de projetos como este para a divulgação do conhecimento, conforme destacado abaixo:

Muito importante, pois é através dela que teremos nossa vacina contra o vírus, enquanto isso ela está nos dando suporte para a prevenção do mesmo (o projeto de extensão nos ajudou muito a compreender questões sobre o vírus que ainda estavam confusas). (Estudante 21)

A ansiedade vivenciada pela sociedade na espera por uma vacina também é identificada nas respostas dos estudantes, pois a questão da vacinação é levantada por $28,6 \%$ dos respondentes, como é possível identificar na resposta a seguir:

A importância da ciência nesse momento pandêmico, na minha opinião, é uma esperança para toda a humanidade, já que ela é a única capaz de encontrar uma vacina e tratamento para o coronavírus. (Estudante 10)

A ciência também foi apontada como uma ferramenta capaz de encontrar a cura para a COVID-19, conforme descrito na resposta abaixo:

A ciência é capaz de encontrar uma solução para o novo coronavírus. (Estudante 06).

Tais respostas evidenciam que, felizmente, os respondentes depositam suas esperanças na ciência para o enfrentamento à pandemia, e possivelmente a execução deste projeto contribuiu para reforçar tais concepções.

\section{Conclusões}

O presente artigo abordou a questão da participação das mulheres na ciência, buscando dar visibilidade ao trabalho por elas realizado, principalmente no que diz respeito às pesquisas para combater o novo coronavírus (SARS-CoV-2), que resultou na pandemia causada pela COVID-19. Neste contexto, também foram apresentadas algumas mulheres cujas contribuições para a ciência ficaram registradas historicamente.

De modo geral, os estudantes avaliaram de forma positiva a execução do projeto. No entanto, observou-se maior participação de estudantes do sexo feminino, tanto nas respostas ao questionário quanto na participação nas rodas de conversa. Constatou-se, ainda, que todos os respondentes afirmaram não conhecer, antes da execução do projeto, as cientistas apresentadas. Trata-se de um dado preocupante porque evidencia a falta de referências femininas na ciência, o que acaba por impactar na escolha profissional futura de estudantes, especialmente das meninas. Os discentes também avaliaram de forma bastante positiva o papel da 
ciência no enfrentamento à pandemia causada pela COVID-19, apontando-a, na maioria das vezes, como uma eficaz estratégia no enfrentamento à crise sanitária vigente.

O conjunto de resultados obtidos confirmou o quanto é necessário debater sobre a temática mulher e ciência na educação básica, especialmente de forma contextualizada, para que meninas sintam-se representadas e encorajadas a seguirem carreiras científicas. Além disso, é importante que todos os conhecimentos científicos apresentados se façam presentes na escola, por meio da realização de outros projetos dessa natureza, para que, assim, a ciência não seja tratada de forma mítica e/ou fantasiosa, e sim como uma maneira sistemática de ler o mundo em que se vive.

\section{Referências}

A BRASILEIRA por trás da vacina de Oxford contra o coronavírus. Fantástico, 2020. Disponível em: https://g1.globo.com/fantastico/podcast/isso-efantastico/noticia/2020/06/28/45-isso-e-fantastico-a-brasileira-por-tras-da-vacina-de-oxfordcontra-o-coronavirus.ghtml. Acesso em: 3 fev. 2021.

ANTENEODO, C.; BRITO, C.; ALVES-BRITO, A.; ALEXANDRE, S. S.; D’AVILA, B. D.; MENEZES, D. P. Brazilian physicists community diversity, equity, and inclusion: A first diagnostic. Physical Review Physics Education Research, v. 16, n. 010136, 2020.

BELTRÃO, K. I.; ALVES, J. E. D. A reversão do hiato de gênero na educação brasileira no século XX. Cadernos de Pesquisa, v. 39, n. 136, p.125-156, jan./abr. 2009.

BRASIL. ONU MULHERES. Gênero e Covid-19 na América Latina e no Caribe: dimensões de gênero na resposta. Casa das Nações Unidas. Brief, 2020.

CARVALHO, M. G.; CASAGRANDE, L. S. Mulheres e ciência: desafios e conquistas. INTERthesis: International Interdisciplinary Review, v. 8, n. 2, p. 20-35, 2011.

CHASSOT, A. A ciência é masculina? É, sim senhora! Revista Contexto \& Educação, v. 19, n. 71-72, p. 9-28, 2004.

CIRURGIÃ dentista brasileira é a primeira voluntária a receber o teste da vacina contra o novo coronavírus. Crosp, 2020. Disponível em: http://www.crosp.org.br/noticia/ver/40970107-cirurgi-dentista-brasileira-a-primeira-voluntria-a-receber-o-teste-da-vacina-contra-onovo-coronavrus.html. Acesso em: 3 fev. 2021.

CRUZ, B. S. Ester Sabino, a médica que agilizou o sequenciamento do novo coronavírus. Tilt, São Paulo, 07 dez. 2020. Disponível em: https://www.uol.com.br/tilt/noticias/redacao/2020/12/07/ester-sabino-sequenciou-ogenoma-do-novo-coronavirus-em-tempo-recorde.htm. Acesso em: 05 jan. 2021. 
DANIELA TRIVELLA e a busca pela cura. Serrapilheira, 19 maio 2020. Disponível em: https://serrapilheira.org/daniela-trivella-e-a-busca-pela-cura/. Acesso em: 3 fev. 2021.

GIL, A. C. Métodos e técnicas de pesquisa social. 6. ed. São Paulo: Atlas, 2008.

HORA, A. S. A descoberta do primeiro Coronavírus humano foi graças a uma mulher. UFABC Divulga Ciência, v.3, n.5, maio 2020. Disponível em: http://proec.ufabc.edu.br/ufabcdivulgaciencia/2020/05/13/a-descoberta-do-primeirocoronavirus-humano-foi-gracas-a-uma-mulher-v-3-n-5-p-7-2020/. Acesso em: 3 fev. 2021.

KERGOAT, D. O cuidado e a imbricação das relações sociais. In: ABREU, A. R. P. et al.

(Orgs). Gênero e trabalho no Brasil e na França. Tradução de Carol de Paula. 1. ed. São Paulo: Boitempo, 2016. p. 17-26.

LAZZARINI, A. B.; SAMPAIO, C. P.; GONÇALVES, V. S.; NASCIMENTO, E. R. F.; PEREIRA, F. M. V.; FRANÇA, V. V. Mulheres na Ciência: papel da educação sem desigualdade de gênero. Revista Ciência em Extensão, v. 14, n. 2, p. 188-194, 2018.

MARQUES, M. C.; XAVIER, K. R. A gênese do movimento feminista e sua trajetória no Bradul. In. SEMINÁRIO CETROS: CRISE E MUNDO DO TRABALHO NO BRASIL. DESAFIOS PARA A CLASSE TRABALHADORA, 6., 2018, Ceará. Anais eletrônicos [...] Itaperi: UECE, 2018. Disponível em:

http://www.uece.br/eventos/seminariocetros/anais/trabalhos_completos/425-5123716072018-192558.pdf. Acesso em: 3 fev. 2021.

MARTINS, A. P. A. O sujeito "nas ondas" do Feminismo e o lugar do corpo na contemporaneidade. Revista Café com Sociologia, v. 4, n. 1, 2015.

OLINTO, G. A inclusão das mulheres nas carreiras de ciência e tecnologia no Brasil. Inclusão Social, v. 5, n. 1, 2011.

PINTO, C. R. J. Feminismo, história e poder. Rev. Sociol. Polit., Curitiba, v. 18, n. 36, p. 15-23, jun. 2010.

PINTO, E. J. S.; AMORIM, V. G. Gênero e educação superior: um estudo sobre as mulheres na Física. 2015. In: REUNIÃO DA ANPEd, 37., 2015, Florianópolis. Anais [...]. Trabalho apresentado no GT23 - Gênero, Sexualidade e Educação. Florianópolis, 2015.

PRODANOV, C. C.; FREITAS, E. C. Metodologia do trabalho científico [recurso eletrônico]: métodos e técnicas da pesquisa e do trabalho acadêmico. 2. ed. Novo Hamburgo: Feevale, 2013.

ROSA, K.; SILVA, R. G. S. Feminismos e ensino de ciências: análise de imagens de livros didáticos de Física. Revista Gênero, n. 10, p. 369-397, 2012. 
SANTOS, A. P.; TOSI, L. Resgatando Metis: O que foi feito desse saber? Revista Estudos Feministas, v. 4, n. 2, p. 355-380, 1996.

SCHIEBINGER, L. O feminismo mudou a ciência? Bauru: EDUSC, 2001.

SILVA, F. F.; RIBEIRO, P. R. C. Trajetórias de mulheres na ciência: "ser cientista" e "ser mulher”. Ciência \& Educação (Bauru), v. 20, n. 2, p. 449-466, 2014.

SILVEIRA, C.; OLIVEIRA, C. K. B. M.; PANTANO, G.; SIMÕES, T. R. G; BARBOSA, A. S.; AMARAL, C. D. B. Mulheres cientistas: Coronavírus., Curitiba: UFPR, 2020.

SOUTO-MARCHAND, A. S.; GALVÃO, E.; FERNANDES, M. (Orgs.). Mulheres Cientistas e os desafios pandêmicos da maternidade: Artigos produzidos durante a Pandemia de Covid-19 em 2020 [recurso eletrônico]. Porto Alegre, RS: Editora Fi, 2020.

STANISCUASKI, F.; REICHERT, F.; WERNECK, F. P.; OLIVEIRA, L.; MELLOCARPES, P. B.; SOLETTI, R. C.; ALMEIDA, C. I.; ZANDONA, E.;

RICACHENEVSKY, F. K.; NEUMANN, A.; SCHWARTZ, I. V. D.; TAMAJUSUKU, A. S. K.; SEIXAS, A.; KMETZSCH, L. Parent in Science Movement. Impact of COVID-19 on academic mothers. Science, v.368, n. 6492, p. 724-724, 2020.

TOSI, L. Mulher e ciência: a revolução científica, a caça às bruxas e a ciência moderna. Cadernos Pagu, n. 10, p. 369-397, 1998. Disponível em: https://periodicos.sbu.unicamp.br/ojs/index.php/cadpagu/article/view/4786705/2352. Acesso em: 3 fev. 2021. 